\title{
Application of the subsecond calorimetry technique with both contact and radiance temperature measurements: case study on solid phase tungsten at very high temperatures
}

\author{
Nenad D. Milošević ${ }^{1}$ (D) \\ Received: 26 June 2020 / Accepted: 23 April 2021 / Published online: 21 June 2021 \\ (c) The Author(s) 2021
}

\begin{abstract}
This work presents an application of the subsecond calorimetry technique at very high temperatures, which uses both contact and radiance temperature measurements. This technique is normally applied for thermophysical characterization of high temperature solid phase materials in the temperature range from ambient up to about $2600 \mathrm{~K}$, which is the limit of the standard tungsten-rhenium thermocouple use. Simultaneously with contact temperature measurements, noncontact or radiance temperature detection may be performed in the approximate range from 1000 to $2600 \mathrm{~K}$ in order to acquire information on spectral normal emissivity of specimen under test. In this study, however, the specimen is heated above $2600 \mathrm{~K}$ and, then, the temperature is measured only by the noncontact mean. In the extended temperature range, the obtained values of the spectral normal emissivity are extrapolated for each experimental run, which makes possible a conversion from radiance to absolute specimen temperature. In order to test this application, a pure polycrystalline specimen of tungsten in the form of rod, $3 \mathrm{~mm}$ in diameter and $200 \mathrm{~mm}$ in length, has been used. The specimen has been heated in vacuum environment of about $10^{-4} \mathrm{mbar}$ by short pulses of high DC current with a gradual increase of the total heating time from about $0.5-2.5 \mathrm{~s}$. During the specimen heating and the beginning of the cooling period, four sets of experimental data have been recorded and reduced by using the corresponding data reduction procedure. Obtained results of specific heat and specific electrical resistivity from ambient to $3700 \mathrm{~K}$, total hemispherical emissivity from 1000 to $3700 \mathrm{~K}$ and spectral normal emissivity from 1000 to $2600 \mathrm{~K}$ (extrapolated to $3700 \mathrm{~K}$ ) are presented, discussed and compared with related literature data.
\end{abstract}

Keywords Specific heat $\cdot$ Specific electrical resistivity $\cdot$ Total hemispherical emissivity $\cdot$ Normal spectral emissivity $\cdot$ High temperatures $\cdot$ Subsecond calorimetry technique

\section{Introduction}

Many dynamic and quasi-dynamic experimental techniques for the determination of specific heat and other thermophysical properties of electrically conductive solid materials have been proposed and used since the beginning of twentieth century. They differ mostly depending on the applied power source which delivers the energy to the specimen and on the way of measurements of this energy and other specific quantities, especially the specimen temperature. Typically, the power sources have been either batteries or electrical capacitors, while the measurement of the specimen temperature

Nenad D. Milošević

nenadm@vinca.rs

1 Institute VINČA, University of Belgrade, Belgrade, Serbia has been direct, by using thermocouples or indirect, by using previously known function between the specimen electrical resistance and temperature. On the other hand, for applications at high and very high temperatures, due to increased heat transfer and dissipation, possible chemical reactions between the specimen and environment and mechanical stress of the specimen, the measurement time should be short as much as possible. In that sense, a method of fast specimen heating was proposed in 1970 by Cezairliyan et al. [1]. In their work, the specimen temperature was measured without contact, i.e., by a high-speed photoelectric pyrometer. The specimen used was in the form of a tube with a tiny centered hole through which radiation passed towards the pyrometer. Assuming a black body radiation from the hole, recorded radiance temperature was equaled to the absolute specimen temperature. The authors initially applied this method for the determination of specific heat 
and other thermophysical properties of molybdenum in the range from 1900 to $2800 \mathrm{~K}$.

Although many high temperature materials have been characterized by pulse heating facilities based on the same or similar radiation thermometry as in Ref. [1], the contact thermometry, providing directly the data of absolute specimen temperature, has been still used in cases when the applied heating rate is not too fast (below millisecond resolution) and the temperature range not too high (above $2600 \mathrm{~K}$ ). Application of such a measuring facility was reported in 1985 by Dobrosavljević and Maglić [2], who first proposed specific data reduction for the obtained thermocouple signals and later provided a corresponding error analysis [3]. Soon after, Maglić et al. [4] upgraded this facility and related measurement procedure in terms of applying both contact and noncontact measurements of the specimen temperature. This has been later used by different authors for the characterization of several high temperature metallic elements up to $2600 \mathrm{~K}$, such as that of molybdenum [5], tantalum [6], hafnium [7], rhodium [8] and ruthenium [9].

In this research, an application of the subsecond calorimetry technique with both contact and radiance temperature measurement has been proposed above the temperature of $2600 \mathrm{~K}$, which is the approximate limit of the standard contact thermometry. Measurements at very high temperatures have been made by using a high-speed pyrometer, but in contrast to techniques based on the method of Cezairliyan et al. [1] and that of Maglić et al. [4] this one uses the estimated values of spectral normal emissivity for each experimental run in order to convert the measured radiance temperature to the absolute temperature of the specimen. As a black-body approximation is not used in temperature measurements, the specimen does not need to have a hole in its center or to be in the form of a tube. Instead, it may take the form of a solid rod, which generally makes its manufacturing more convenient and cost effective.

This work is a part of a European joint research project ${ }^{1}$ aiming to establish reference facilities for measuring the specific heat of high temperature solids at temperatures up to about $3000{ }^{\circ} \mathrm{C}(\sim 3300 \mathrm{~K})$. The considered facilities are based on one stationary, the drop calorimetry method and two dynamic, the laser flash and the subsecond calorimetry techniques. In order to fulfill the goal regarding the temperature range, this work proposes a new measurement principle of the subsecond calorimetry technique and provides first results obtained on a pure tungsten specimen by using the related experimental facility of the Institute VINČA.

\section{Principle}

The purpose of the subsecond calorimetry technique is to measure the specific heat of an electro-conductive solid material at high temperatures and its principle is as follows: Heat rapidly a specimen with an electrical current pulse, $i$, and monitor simultaneously a voltage drop over the specimen, $u$, and its transient temperature, $T$. By knowing the specimen temperature and the total energy absorbed by the unit specimen mass, decreased by the total radiation heat losses, the specific heat of the specimen material can be determined, together with its specific electrical resistivity and total hemispherical emissivity.

The measurement of the specimen temperature is crucial here. It can be performed either by contact or noncontact thermometry. For the case of the contact temperature measurement only, a detailed measurement and data reduction procedure is given in Ref. [3]. However, in order to measure the properties at very high temperatures, but still keeping advantages of the contact thermometry, a simple principle in four stages is proposed here: Measure the specimen temperature by using simultaneously contact and noncontact thermometry and find all the three properties of the specimen, as well as its spectral normal emissivity, up to the limit of the used contact temperature sensor $T_{\text {cmax }}(\sim 2600 \mathrm{~K}$ for the $\mathrm{C}$ type thermocouple, for example) [4]; extrapolate the obtained values on spectral normal emissivity above this temperature limit for each experimental run; convert the measured radiance temperature, $T_{\lambda}$, to the absolute specimen temperature, $T$, and, finally, find the values of other three properties over the extended temperature range. A flowchart of such a measurement procedure is given in Fig. 1, where $\rho$ is the specific electrical resistivity, $\varepsilon_{\mathrm{th}}$ total hemispherical emissivity, $c_{\mathrm{p}}$ specific heat and $\varepsilon_{\lambda_{\mathrm{n}}}$ spectral normal emissivity of the specimen material.

As short wavelengths $(\lambda<1 \mu \mathrm{m})$ are usual for a high temperature detection of the radiance temperature, the spectral normal emissivity, derived from Planck's law and the spectral radiance of a gray body [10], may be reduced to $\varepsilon_{\lambda \mathrm{n}} \approx c_{2} \lambda^{-1} \mathrm{e}^{c_{2} / \lambda\left(T^{-1}-T_{\lambda}^{-1}\right)}$, where $c_{2}$ is the second radiation constant. From this formula, if both measured and extrapolated spectral normal emissivity values are written as $\varepsilon_{\lambda \mathrm{n}}^{\prime}(T)$ and the measured radiance temperature in function of time as $T_{\lambda}(t)$, the conversion to the absolute temperature above $T_{\text {cmax }}$ is made by:

$T(t)=\frac{T_{\lambda}(t)}{1+T_{\lambda}(t) \frac{\lambda}{c_{2}} \ln \left[\varepsilon_{\lambda \mathrm{n}}^{\prime}(T)\right]}$

As this equation is intrinsic in regards to the absolute temperature $T$, it must be solved numerically. If all the spectral normal emissivity values is fitted, for example, by a linear function

$\overline{1}$ http://www.hi-trace.eu/. 


Stage I: Find $\rho, \varepsilon_{\mathrm{th}}, c_{p}$
and $\varepsilon_{\lambda \mathrm{n}}$ up to $T_{\mathrm{cmax}}$ by
using the data
reduction from [4]

\section{Stage II: Extrapolate the obtained $\varepsilon_{\lambda \mathrm{n}}$ values above $T_{\mathrm{cmax}}$}

Stage III: Convert
the measured
radiance temperature
to the absolute one
above $T_{\text {cmax }}$

Stage IV: Find $\rho, \varepsilon_{\text {th }}$ and $c_{p}$ above $T_{\text {cmax }}$ by using the converted values and data reduction from [4]

Fig. 1 Flowchart of the proposed measurement procedure

$\varepsilon_{\lambda \mathrm{n}}^{\prime}(T)=a_{0}+a_{1} T$

the iterative equation for computing the absolute temperature values from Eq. (1) may be found by the Newton-Rapson

$$
T_{\mathrm{k}+1}\left(t_{\mathrm{i}}\right)=T_{\mathrm{k}}\left(t_{\mathrm{i}}\right)-\frac{a_{0}+a_{1} T_{\mathrm{k}}\left(t_{\mathrm{i}}\right)-\mathrm{e}^{\frac{\mathrm{c}_{2}}{\lambda}\left[\frac{1}{T_{\mathrm{k}}\left(t_{\mathrm{i}}\right)}-\frac{1}{T_{\lambda}\left(t_{\mathrm{i}}\right)}\right]}}{a_{1}+\frac{\mathrm{c}_{2}}{\lambda T_{\mathrm{k}}^{2}\left(t_{\mathrm{i}}\right)} \mathrm{e}^{\frac{\mathrm{c}_{2}}{\lambda}\left[\frac{1}{T_{\mathrm{k}}\left(t_{\mathrm{i}}\right)}-\frac{1}{T_{\lambda}\left(t_{\mathrm{i}}\right)}\right]}}
$$

method [11] as

Fig. 2 Schematic of the experimental setup

Fig. 3 The values of $\rho$ up to and above $T_{\text {cmax }}$
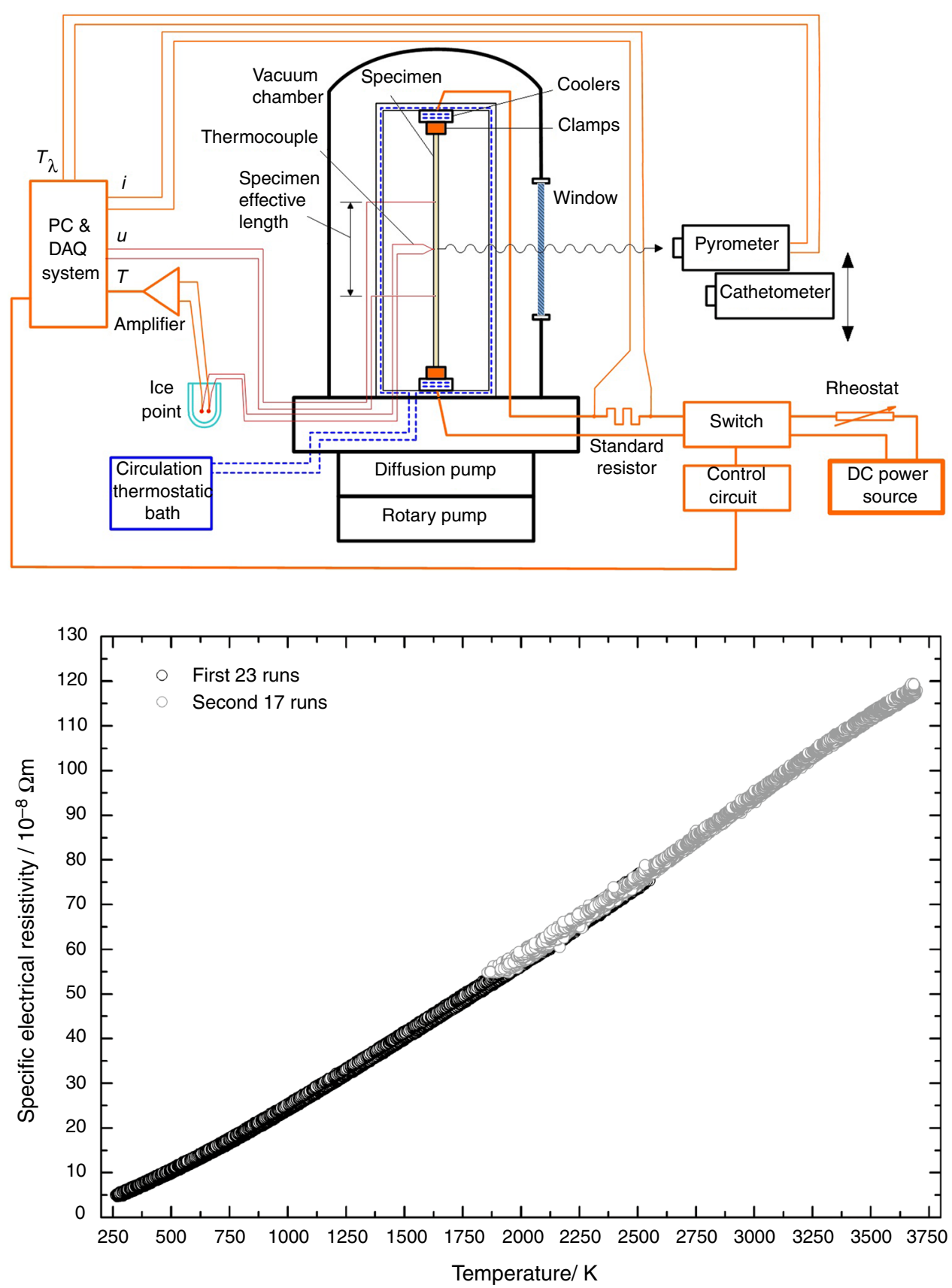
Fig. 4 The values of $\varepsilon_{\mathrm{th}}$ up to and above $T_{\text {cmax }}$

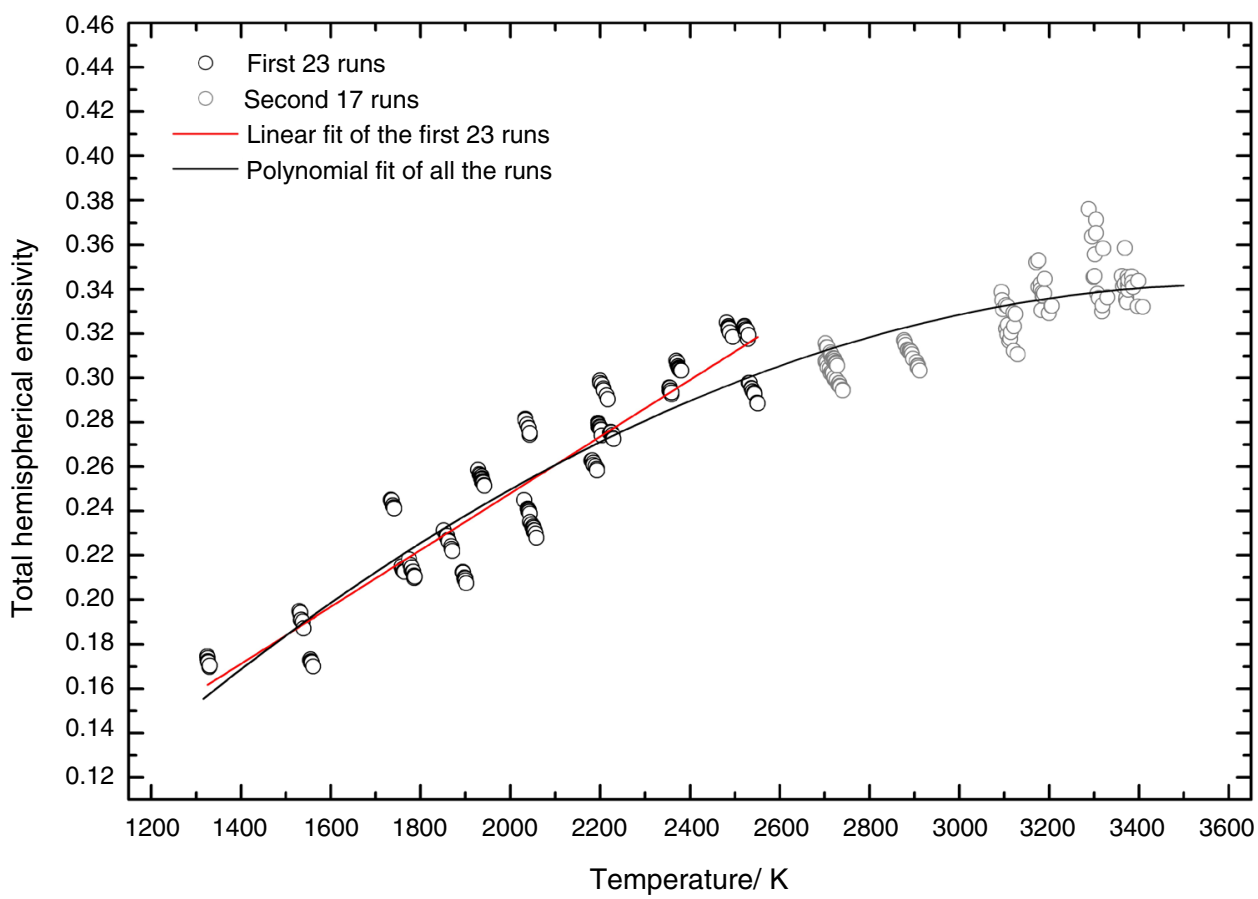

where $k$ is the iteration number, and $i$ is the time step above $T_{\text {cmax }}$. For higher order fittings of $\varepsilon_{\lambda \text { n }}^{\prime}$ values, related iterative equations may be accordingly derived.

\section{Experimental}

\section{Setup}

The proposed measurement principle has been applied by using an experimental facility based on the subsecond calorimetry with both contact and noncontact thermometry. The facility consists of special specimen holders, cooling unit, environmental chamber, high current pulse circuitry, sensing and detection unit and data acquisition and control system. Schematic of the facility is presented in Fig. 2, and its detailed description is given in Refs. [3, 4].

\section{Specimen}

A specimen of pure polycrystalline tungsten was provided by Goodfellow Cambridge Ltd. It had the form of a thin rod, $3 \mathrm{~mm}$ in diameter and $200 \mathrm{~mm}$ in length, nominally. Its chemical purity was claimed to be greater than $99.95 \%$ by mass. The specimen was manually polished by using fine grade sandpapers. According to the final measured dimensions and mass of the specimen and their related uncertainties, the specimen density was estimated to be
$(19.27 \pm 0.03) \mathrm{kg} \mathrm{m}^{-3}$ in comparison with $19.25 \mathrm{~kg} \mathrm{~m}^{-3}$ of pure tungsten [12].

\section{Measurements}

The specimen was placed between the clamps inside the chamber where the air was evacuated to about $10^{-4}$ mbar. Its stationary specimen temperature was maintained by conduction from the coolers to about $0{ }^{\circ} \mathrm{C}$. For both transient and stationary contact temperature measurement, thermocouple leads of C type (W95\%/Re5\%-W74\%/Re26\%) and $70 \mu \mathrm{m}$ in diameter were intrinsically welded on the specimen center. The voltage drop was measured by thin wires of pure tungsten, also $70 \mu \mathrm{m}$ in diameter and welded at the distance of about $20 \mathrm{~mm}$, which was the actual length of the specimen effective part. The radiance temperature was measured by a high-speed pyrometer, having the nominal wavelength of $900 \mathrm{~nm}$ and a powerful focusing optics of a less than $2 \mathrm{~mm}$ field of view at a distance of $400 \mathrm{~mm}$. The pyrometer was focalized in a close vicinity to the welded thermocouple leads. As heat radiation from the specimen was detected from outside the chamber, a window's measured transparency of 0.58 at $900 \mathrm{~nm}$ was included in the computation of the specimen radiance temperature. One and two in series high current, $12 \mathrm{~V}$ dc power sources were used for the specimen heating with approximate heating rates of $700 \mathrm{~K} \mathrm{~s}^{-1}$ and $2000 \mathrm{~K} \mathrm{~s}^{-1}$, respectively. 
Fig. 5 The values of $c_{\mathrm{p}}$ up to and above $T_{\text {cmax }}$
Fig. 6 The typical values of $\varepsilon_{\lambda \mathrm{n}}$ up to $T_{\mathrm{cmax}}$ and their linear extrapolation above $T_{\text {cmax }}$
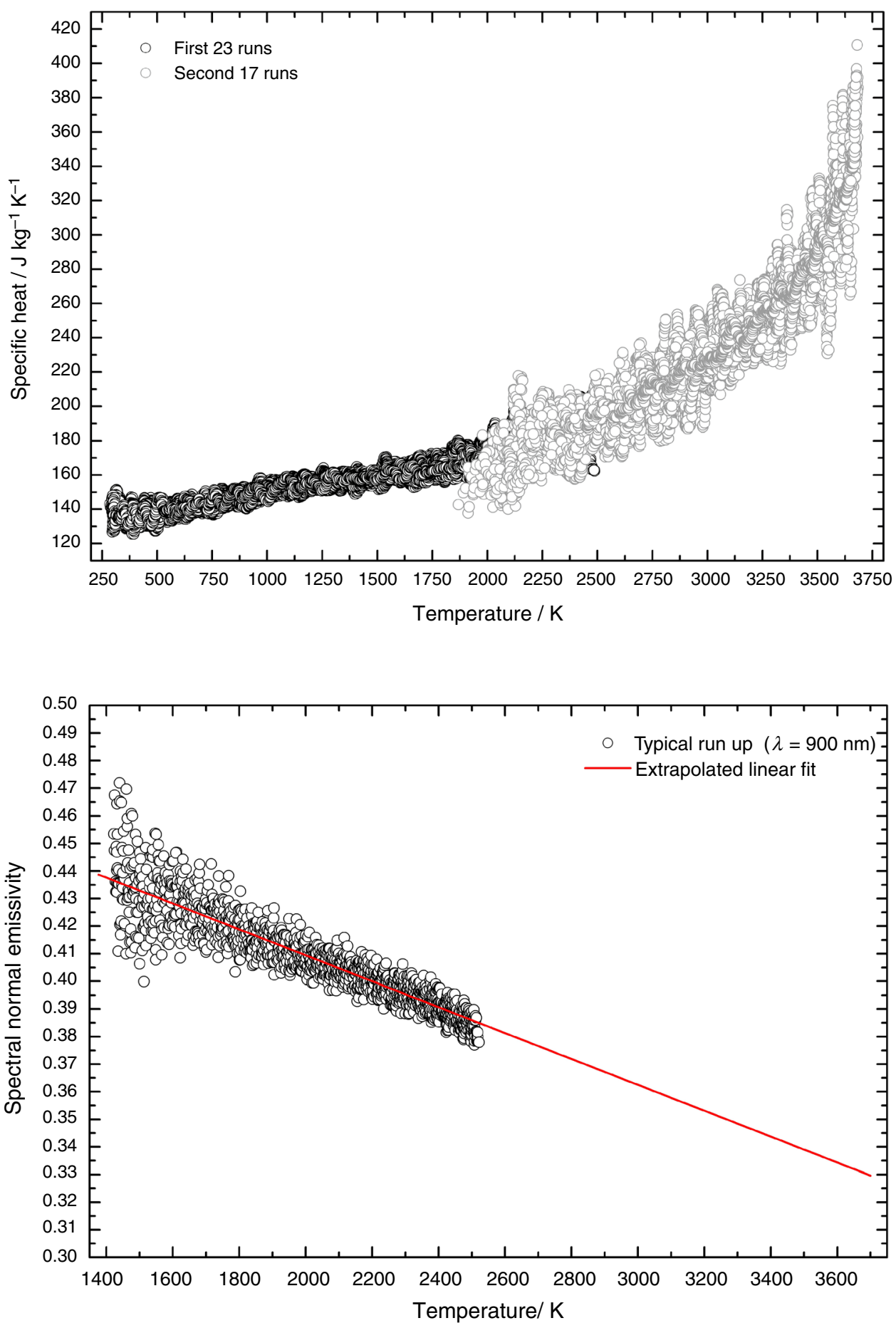

\section{Results}

In total, 40 experimental runs have been performed on the same specimen. Heating time and, therefore, the maximum specimen temperature, was gradually increased in order to determine an adequate number of the total hemispherical emissivity values. First 23 runs were made up to $T_{\text {cmax }} \approx 2600 \mathrm{~K}$, which is the limit of the $\mathrm{C}$ type thermocouple standard function, while the rest of 17 runs were all recorded at temperatures above $2600 \mathrm{~K}$, i.e., up to about $3700 \mathrm{~K}$.

By first using the data reduction procedure from Ref. [4], the non-averaged values of $\rho$ obtained from the measurement of voltage drop, current and absolute specimen temperature (first 23 runs, up to $T_{\text {cmax }}$ ) are given in Fig. 3, while those of $\varepsilon_{\mathrm{th}}$, together with their linear fit are given in Fig. 4 (Stage I, 
Fig. 7 Comparison among the obtained values of $\rho$ and those recommended
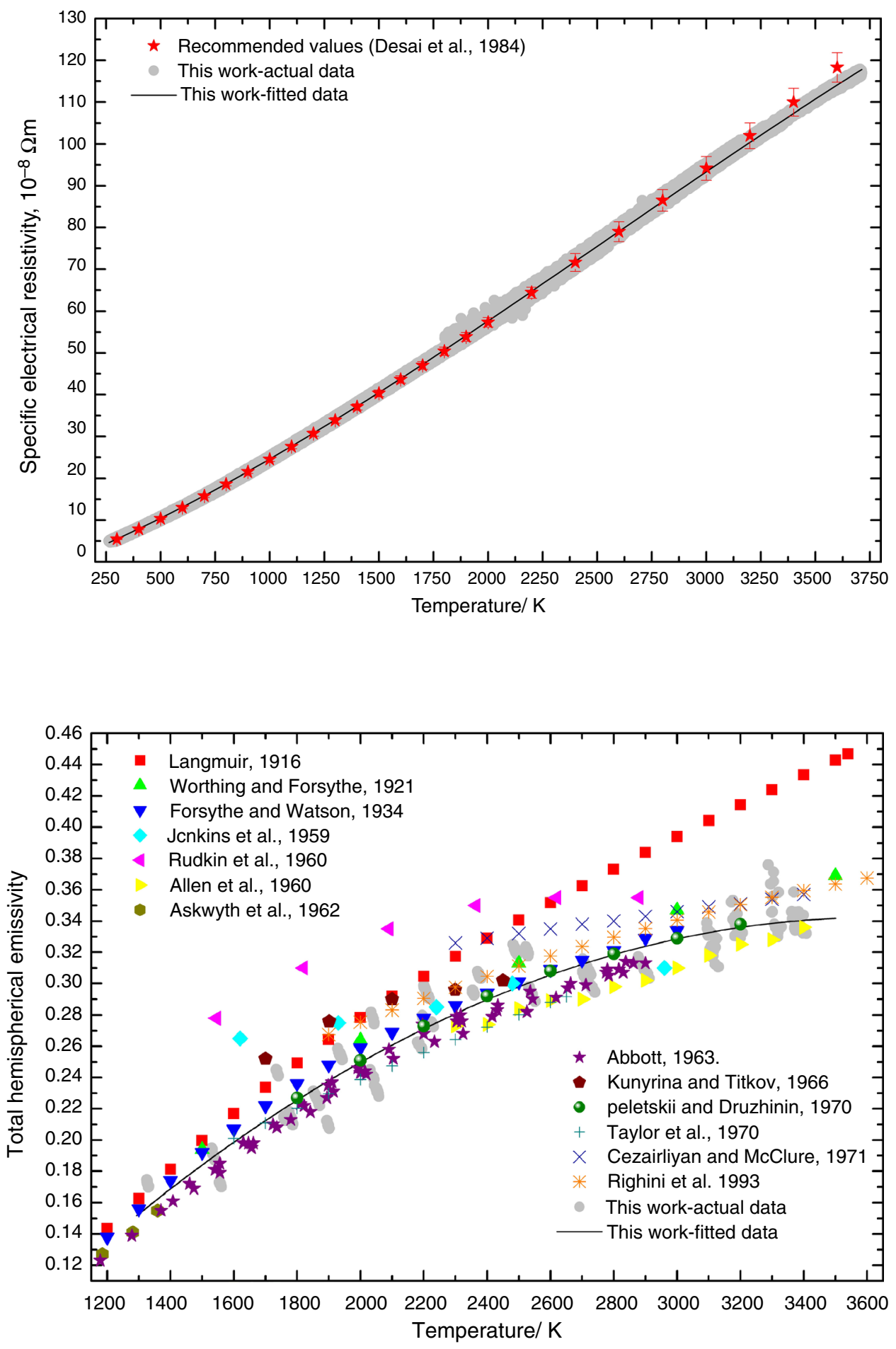

Fig. 8 Comparison among the obtained values of $\varepsilon_{\text {th }}$ and those from the literature black circles). The latter ones were used for the calculation of $c_{\mathrm{p}}$ (Fig. 5, black circles). On the other hand, the values of $\varepsilon_{\lambda \mathrm{n}}$ from a typical set of absolute and radiance temperature data up to $T_{\text {cmax }}$ and their linear extrapolation above this temperature, Eq. (2), are presented in Fig. 6 (Stage II).
Having the estimated values of $\varepsilon_{\lambda \mathrm{n}}$ and radiance temperature converted to the absolute temperature for each experimental run above $T_{\text {cmax }}$ from Eq. (3) (Stage III), the values 
Fig. 9 Comparison among the obtained values of $c_{\mathrm{p}}$ and those from the literature

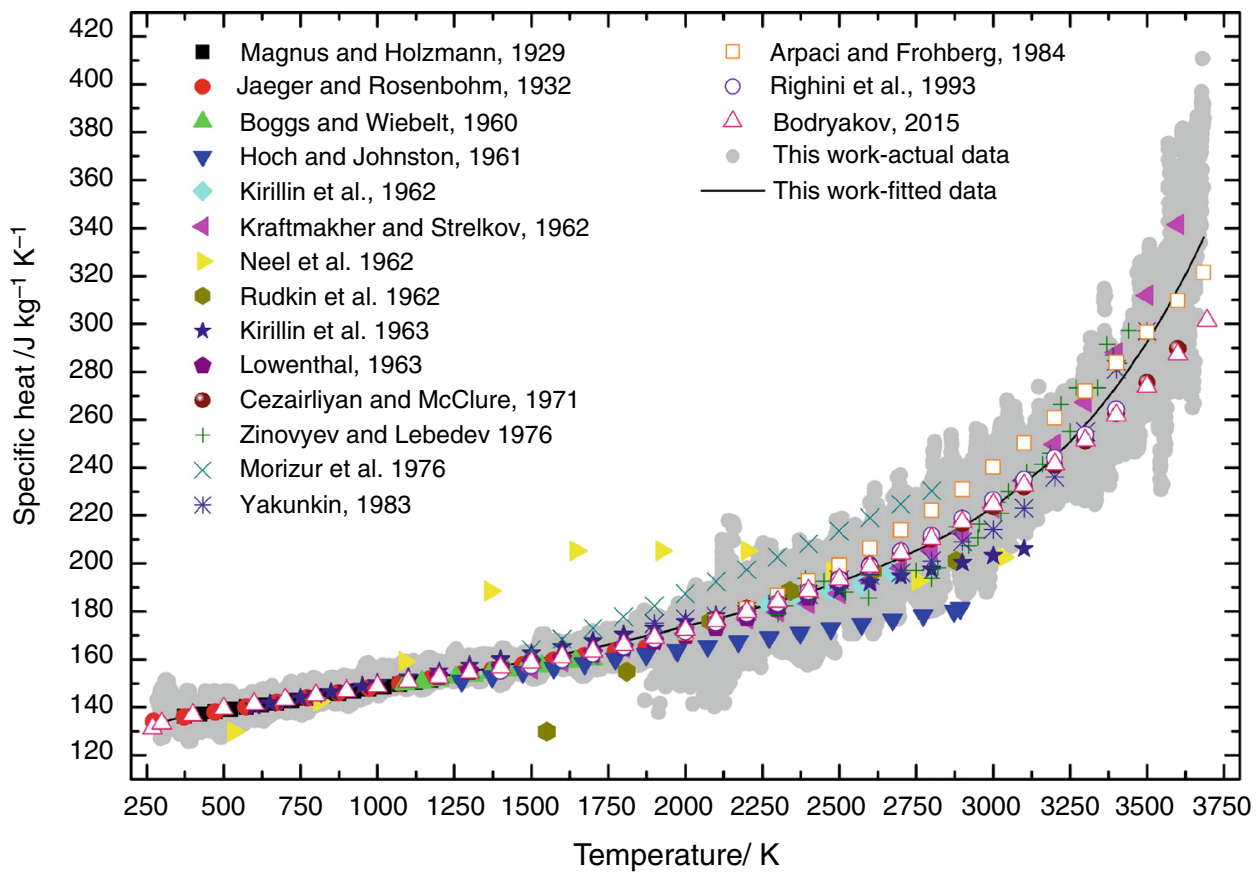

of specific electrical resistivity and total hemispherical emissivity were computed in the higher temperature range (Stage IV, Figs. 3 and 4, gray circles). At last, the values of $\varepsilon_{\text {th }}$ were re-smoothed with a new polynomial $\mathrm{fit}^{2}$ and used for the determination of specific heat in the whole temperature range (Stage IV). The final non-averaged values of $c_{\mathrm{p}}$ in the higher temperature range are presented in Fig. 5, gray circles.

\section{Discussion}

In order to evaluate correctness of the proposed principle and measurement, the obtained results are fitted and compared with the available high temperature literature data of pure tungsten. First, a comparison among the fitted data of specific electrical resistivity ${ }^{3}$ with those recommended by Desai et al. [13] is given in Fig. 7. A high level of coincidence can be observed within the whole temperature range, except at highest temperatures, where a difference of about $3 \%$ emerges between the recommended and actual results. Such the difference, however, may be overridden by the final total measurement uncertainty of $\rho$ at these temperatures.

Considering the total hemispherical emissivity, both its non-averaged and fitted values are compared with several sets of available literature data [14-26], as presented in Fig. 8. It can be seen a good agreement among actual and several sets of literature data, especially in their tendency with a temperature change. Finally, for the specific heat, a comparison among the obtained values and the available literature data [27-41] is presented in Fig. 9. Most literature data reveal an uprise of specific heat values with temperature, so do the actual measurements. After their further reduction with a polynomial fit, ${ }^{4}$ it can be observed that the final results of specific heat coincide very well with most literature data, i.e., within less than $10 \%$ at highest temperatures.

With regard to the measurement uncertainty, Stage II is crucial: Results of the extrapolation directly influence the converted temperature values of Stage III, which further makes a direct impact to the final values of Stage IV. In other words, uncertainty of the extrapolated spectral normal emissivity above $T_{\text {cmax }}$ directly contributes to the total horizontal uncertainty of three measured properties, i.e., to their temperature uncertainty. As this contribution may be particularly important in cases when specific heat and specific electrical resistivity values strongly depend on temperature, special care should be taken in practice for the realization of Stage II of the proposed measurement procedure.

\footnotetext{
${ }^{2} \varepsilon_{\mathrm{th}}=-0.118+2.541 \times 10^{-4} T-3.504 \times 10^{-8} T^{2}(T / \mathrm{K})$.

${ }^{3} \rho / 10^{-8} \Omega \mathrm{m}=-1.219+2.064 \times 10^{-2} T+5.944 \times 10^{-4}$ $T^{2}-7.725 \times 10^{-8} T^{3}(T / \mathrm{K})$.
}

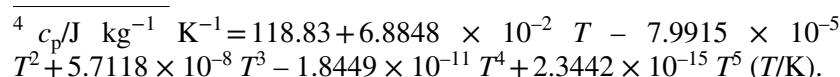




\section{Conclusions}

The standard use of the subsecond calorimetry technique implies the temperature measurements either by radiation or contact thermometry. While the both methods of temperature measurements have their advantages and disadvantages, this work proposes their simultaneous use which allows a measurement of the specimen spectral normal emissivity up to the temperature limit of the contact thermometry. Then, above that limit, the obtained values of the spectral normal emissivity are extrapolated, letting the recorded radiance temperature to be converted to the absolute specimen temperature. The latter values are finally used to estimate the specific electrical resistivity, total hemispherical emissivity and specific heat at very high temperatures.

The proposed principle has been tested on a specimen of pure polycrystalline tungsten. Obtained results of all the measured properties show good agreement with related literature data, but also suggest that radiance to absolute temperature conversion needs to be considered carefully due to its potentially significant influence on the final temperature uncertainty of presented results.

Acknowledgements This work has been accomplished through EMPIR 17IND11 Hi-TRACE joint research project. The project EMPIR 17IND11 Hi-TRACE has received funding from the EMPIR programme co-financed by the Participating States and from the European Union's Horizon 2020 research and innovation programme.

Open Access This article is licensed under a Creative Commons Attribution 4.0 International License, which permits use, sharing, adaptation, distribution and reproduction in any medium or format, as long as you give appropriate credit to the original author(s) and the source, provide a link to the Creative Commons licence, and indicate if changes were made. The images or other third party material in this article are included in the article's Creative Commons licence, unless indicated otherwise in a credit line to the material. If material is not included in the article's Creative Commons licence and your intended use is not permitted by statutory regulation or exceeds the permitted use, you will need to obtain permission directly from the copyright holder. To view a copy of this licence, visit http://creativecommons.org/licenses/by/4.0/.

\section{References}

1. Cezairliyan A, Morse MS, Berman HA, Beckett CW. High-speed (subsecond) measurement of heat capacity, electrical resistivity, and thermal radiation properties of molybdenum in the range 1900 to 2800 K. J Res Natl Bur Stand. 1970;74A:65-92.

2. Dobrosavljević AS, Maglić KD. Pulse heating method for specific heat and electrical resistivity measurement in the range 300 to 1400 K. In: Soloukhin RI, Afgan N, editors. Advanced course in measurement techniques in heat and mass transfer. Washington: Hemisphere; 1985. p. 411-20.

3. Dobrosavljević AS, Maglić KD. Evaluation of a direct pulse heating method for measurement of specific heat and electric resistivity in the range 300-1900 K. High Temp High Press. 1989;21:411-21.

4. Maglić KD, Perović NL, Vuković GS, Zeković LP. Specific heat and electrical resistivity of niobium measured by subsecond calorimetric technique. Int J Thermophys. 1994;15:963-72.

5. Maglić KD, Perović NL, Vuković GS. Specific heat and electric resistivity of molybdenum between 400 and $2500 \mathrm{~K}$. High Temp High Press. 1997;29:97-102.

6. Milošević ND, Vuković GS, Pavičić DZ, Maglić KD. Thermal properties of tantalum between 300 and $2300 \mathrm{~K}$. Int J Thermophys. 1999;20:1129-36.

7. Milošević ND, Maglić KD. Thermophysical properties of solid phase hafnium at high temperatures. Int J Thermophys. 2006;27:530-53.

8. Milošević ND. Thermophysical properties of solid phase rhodium measured by the pulse calorimetry technique over a wide temperature range. Int J Mater Res. 2014;105:571-6.

9. Milošević ND, Nikolić ID. Thermophysical properties of solid phase ruthenium measured by the pulse calorimetry technique over a wide temperature range. Int J Mater Res. 2015;106:361-7.

10. Siegel R, Howell JR. Thermal radiation heat transfer. 2nd ed. Washington: Hemisphere; 1981.

11. Süli E, Mayers D. An introduction to numerical analysis. 1st ed. Cambridge: Cambridge University Press; 2003.

12. Kaye GWC, Laby TH. Tables of physical and chemical constants. 16th ed. London: Longman Scientific \& Technical; 1995.

13. Desai PD, Chu TK, James HM, Ho CY. Electrical resistivity of selected elements. J Phys Chem Ref Data. 1984;13:1069-96.

14. Langmuir I. The characteristics of tungsten filaments as functions of temperature. Phys Rev. 1916;7:302-30.

15. Worthing AG, Forsythe WE. Total emissive power and resistivities of W at incandescence. Phys Rev. 1921;18:144-7.

16. Forsythe WE, Watson EM. Resistance and radiation of tungsten as a function of temperature. J Opt Soc Am. 1934;24:114-8.

17. Jenkins RJ, Parker WJ, Butler CP. Thermal properties of metals. USNRDL-TR-348; 1959.

18. Rudkin RL, Parker WJ, Westover RW. Properties of metals at high temperatures. USNRDL-TR-419; 1960.

19. Allen RD, Glasier LF Jr, Jordan PL. Spectral emissivity, total emissivity, and thermal conductivity of molybdenum, tantalum, and tungsten above $2300^{\circ} \mathrm{K}$. J Appl Phys. 1960;31:1382-7.

20. Askwyth WH, Yahes RJ, House RD, Mikk G. Determination of the emissivity of materials. NASA-CR-56496-56498; 1962.

21. Abbott GL. Total normal and total hemispherical emittance of polished metals - part III. WADD-TR-61-94; 1963.

22. Kunyrina LI, Titkov AS. One method of measuring reduced emissivities for a coaxial system of surfaces. High Temp. 1966;4:394-8.

23. Peletskii VE, Druzhinin VP. The total hemispherical emissivity of tungsten, molybdenum, and rhenium single crystals at high temperatures. High Temp High Press. 1970;2:69-74.

24. Taylor RE, Kimbrough WD, Powell RW. Thermophysical properties of tantalum, tungsten, and tantalum-10 wt.\% tungsten at high temperatures. J Less-Common Metals. 1971;24:369-82.

25. Cezairliyan A, McClure JL. High-speed electrical (subsecond) measurement of heat capacity, resistivity, and thermal radiation properties of tungsten in the range 2000 to 3600 K. J Res Natl Bur Stand. 1971;75A:283-90.

26. Righini F, Spišiak J, Bussolino GC, Rosso A. Measurement of thermophysical properties by a pulse heating method: tungsten, 1200 to 3600 K. High Temp High Press. 1993;25:193-203.

27. Magnus A, Holzmann $\mathrm{H}$. Testings on the specific heat of tantalum, tungsten and beryllium between 100 and 900 degrees C. Ann Phys. 1929;3:585-613.

28. Jaeger FM, Rosenbohm E. Exact determination of the real specific heat of tungsten, rhodium, palladium, ruthenium, osmium and 
iridium at temperatures between 0 and $1625^{\circ} \mathrm{C}$. Rec Trav Chim. 1932;51:1-46.

29. Boggs JH, Wiebelt JA. An investigation of a particular comparative method of specific heat determinations in the temperature range of 1500 to $2600^{\circ}$ F. U.S. At. Energy Comm TID-5734; 1960.

30. Hoch M, Johnston HL. A high temperature drop calorimeter. The heat capacities of tantalum and tungsten between $1000^{\circ}$ and $3000^{\circ}$ K. J Phys Chem. 1961;65:855-60.

31. Kirillin VA, Sheindlin AE, Chekhovskoi VYa. Enthalpy and specific heat of tungsten in the $0-2400^{\circ} \mathrm{C}$ temperature range. Proc Acad Sci USSR. 1962;142:1323-6.

32. Kraftmakher YA, Strelkov PG. Energy of formation and equilibrium vacancy concentration in tungsten. Sov Phys Solid State. 1962;4:1662-4.

33. Neel DS, Pears CD, Oglesby S Jr. The thermal properties of thirteen solid materials to $5000 \mathrm{~F}$ for their destruction temperatures. WADD-TR-60-924; 1962.

34. Rudkin RL, Parker WJ, Jenkins RJ. Measurements of the thermal properties of metals at elevated temperatures. Temp Meas Control Sci Ind. 1962;3:523-34.

35. Kirillin VA, Sheindlin AE, Chikhovskoi VYa, Petrov VA. Thermodynamic properties of wolfram in the temperature range 0-3500 K. Zh Fiz Khim. 1963; 37:2249-56.
36. Lowenthal GC. The specific heat of metals between $1200^{\circ} \mathrm{K}$ and $2400^{\circ}$ K. Austral J Phys. 1963;16:47-67.

37. Zinovyev VE, Lebedev SV. Heat capacity of tungsten at high temperatures. Teplophys Vys Temp. 1976;14:83-6.

38. Morizur G, Radenac A, Cretanet J-C. Application for the determination of specific heat of tungsten. High Temp High Press. 1976;8:113-20.

39. Yakunkin MM. Specific-heat of tungsten by periodic pulsed heating. Teplophys Vys Temp. 1983;21:1115-21.

40. Arpaci E, Frohberg MG. Enthalpy measurements on solid and liquid tungsten by levitation calorimetry. Z Metallkunde. 1984;75:614-8.

41. Bodryakov VYu. Correlation of temperature dependences of thermal expansion and heat capacity of refractory metal up to the melting point: tungsten. High Temp. 2015; 53:643-8.

Publisher's Note Springer Nature remains neutral with regard to jurisdictional claims in published maps and institutional affiliations. 